Pak. j. sci. ind. res. Ser. A: Phys. sci. 2015 58(1) 17-25

\title{
Role of Biodiesel-Diesel Blends in Alteration of Particulate Matter Emanated by Diesel Engine
}

\author{
Asad Naeem Shah ${ }^{\mathrm{a} *}$, Ge Yun-Shan ${ }^{\mathrm{b}}$, Tan Jian-Wei ${ }^{\mathrm{b}}$ and Ejaz Mahmood Shahid ${ }^{\mathrm{a}}$ \\ ${ }^{a}$ Department of Mechanical Engineering, University of Engineering and Technology, \\ Lahore-54000, Pakistan \\ ${ }^{b}$ National Laboratory of Auto Performance and Emission Test, School of Mechanical and \\ Vehicular Engineering, Beijing Institute of Technology, Beijing100081, China
}

(received June 4, 2013; revised April 11, 2014; accepted April 15, 2014)

\begin{abstract}
The current study is focused on the investigation of the role of biodiesel in the alteration of particulate matter (PM) composition emitted from a direct injection-compression ignition. Two important blends of biodiesel with commercial diesel known as B20 (20\% biodiesel and $80 \%$ diesel by volume) and B50 were used for the comparative analysis of their pollutants with those of $100 \%$ or traditional diesel (D). The experiments were performed under the auspices of the Chinese 8-mode steadystate cycle on a test bench by coupling the engine with an AC electrical dynamometer. As per experimental results, over-50 nm aerosols were abated by $8.7-47 \%$ and $6-51 \%$ with B20 and B50, respectively, on account of lofty nitrogen dioxide to nitrogen oxides $\left(\mathrm{NO}_{2} / \mathrm{NO}_{\times}\right)$ratios. In case of B50, sub-50 nm aerosols and sulphates were higher at maximum load modes of the test, owing to adsorption phenomenon of inorganic nuclei leading to heterogeneous nucleation. Moreover, trace metal emissions (TME) were substantially reduced reflecting the reduction rates of $42-57 \%$ and $64-80 \%$ with B20 and B50, respectively, relative to baseline measurements taken with diesel. In addition to this, individual elements such as $\mathrm{Ca}$ and $\mathrm{Fe}$ were greatly minimised, while $\mathrm{Na}$ was enhanced with biodiesel blended fuels.
\end{abstract}

Keywords: biodiesel, unregulated emissions, trace metals, nanoparticles, sulphates, diesel engine

\section{Introduction}

Today biodiesel is considered as one of the most attractive and environmentally benign fuels on account of its better physicochemical properties and combustion as compared to conventio-nal diesel fuel. It is a readily available clean burning fuel which can be used both in blended as well as neat forms without major changes in the engine hardware. Regulated emissions such as carbon monoxide (CO), hydrocarbons (HC) and PM are greatly reduced with biodiesel (He et al., 2009; Shah et al., 2009a; Rehman and Ghadge, 2007; TurrioBaldassarri et al., 2004; Dorado et al., 2003). Moreover, smoke opacity and other unregulated emissions comprising aldehyde and ketones, polycyclic aromatic hydrocarbons (PAHs), and volatile organic compounds (VOCs) are also decreased with this alternative fuel (Shah et al., 2009b; Shah et al., 2008; Jha et al., 2008; Lin et al., 2006). However, oxides of nitrogen $\left(\mathrm{NO}_{\times}\right)$and nuclei mode particles have been reported to be increased with biodiesel (Shah et al., 2014; Shah et al., 2009a, 2009b; Karabektas et al., 2008; Szybist et al., 2007; Usta, 2005).

The performance of engines in terms of brake power, thermal efficiency, and brake specific energy consump-

*Authour for correspondence; E-mail:naeem_138@hotmail.com tion is more or less same with biodiesel or its blends (Shah et al., 2009a, 2009b; Agarwal and Das, 2001). In addition to this, study of combustion parameters such as ignition delay, maximum combustion pressure (MCP), maximum rate of pressure rise, start of injection angle, heat release rate, and combustion zones endorse the superiority of this renewable and biodegradable fuel over the petroleum diesel (Shah at al., 2009a; Tsolakis, 2006; Lee et al., 2005). Further, macroscopic spray characteristics of biodiesel-diesel blended fuel have revealed that both the spray tip penetration and cone angle are increased with biodiesel, relative to diesel (Shah et al., 2010). This reflects the better quality of biodiesel blended fuel, than the neat diesel.

In general, PM is constituted by ashes or trace elements, volatile organic fraction or soluble organic fraction, sulphates and carbon soot, while the composition is affected by several parameters such as engine category, sampling technique, lubricating oil, composition of fuel and type of driving cycle (Zhao et al., 2010). Agarwal (2007) is of the view that PM consists of $40 \%$ unburned lubricating oil, 31\% elemental carbon, $14 \%$ sulphates, $7 \%$ unburned fuel, and $8 \%$ metals along with some other substances. Metals in the emitted particulate matter originate from lube oil, fuel, and engine 
wear along with the gaseous sulphite at higher temperature during the combustion (Lim et al., 2007).

Particulate matter brought forth by a diesel engine exhaust is composed largely of nuclei, accumulation, and coarse mode particles with their respective diameters typically between 5 and $50 \mathrm{~nm}, 50$ and $1000 \mathrm{~nm}$, and higher than $2.5 \mu \mathrm{m}$ (Liu et al., 2011; Wong et al., 2003). Burtscher (2005) had reported that the typical diesel particles are agglomerates comprising spherical particles of diameter 15 to $40 \mathrm{~nm}$. Further, the mean diameter of these agglomerated particles (accumulation mode) remains always in the range of 60 to $100 \mathrm{~nm}$. The substantial numbers of nuclei (sub-50 nm) particles typically contribute just few percent to total mass, and their contribution to the number depends on their size distribution. The size distributions are affected by many parameters including engine operating conditions, exhaust after treatment, fuels, etc. Nuclei mode particles comprise primarily of metallic compounds, carbonaceous nuclei, sulphur compounds and soluble organic fraction, some of which are formed during cooling or dilution processes (Wong et al., 2003; Kittleson, 1998). The probability of nuclei mode particles to be inhaled by human beings is higher owing to their smaller sizes and larger numbers. This may cause respiratory diseases and even lungs cancer (Donaldson et al., 1998). European regulations (Euro 5/6), therefore, have already included particle number measurements along with the total mass of PM.

The objective of the current study is to investigate the influence of biodiesel on the PM composition including nuclei and accumulation mode particles, sulphates and trace metal emissions (TME). Biodiesel-diesel blends B20 and B50 have been used to gain a deep insight into the biodiesel role in above discussed emissions. Earlier, authors (Shah et al., 2014) have reported that accumulation mode particles, total TME, and individual elements such as iron and calcium are greatly reduced, while nuclei mode particles and sodium are increased with neat biodiesel (B100). In addition to this, it has also been pointed out that sulphates are slightly, only $8 \%$, increased with B100 as compared to petroleum diesel. Thus the current study will characterise the PM composition, and will provide the comparative analysis of $\mathrm{B} 20$ and $\mathrm{B} 50$ with conventional diesel. The emission measurements taken with diesel fuel are known here as baseline measurements.

\section{Materials and Methods}

Test engine, operating cycle, fuels and lubricant. A turbocharged inter-cooled DI-CI engine of $4.752 \mathrm{~L}$ capacity was run on an AC electrical dynamometer (Schenck HT350, Germany) on a test bench following an 8 Mode steady-state cycle ISO 8178 Type C1 (Shah et al., 2011). The engine has four cylinders with compression ratio of 16.8: 1 . The bore and stroke are 110 and $125 \mathrm{~mm}$, respectively, while the injector has 6 holes/nozzles of $0.23 \mathrm{~mm}$ diameter each. The maximum torque and power of the engine are 580 $\mathrm{N}-\mathrm{m}$ and $117 \mathrm{~kW}$ at crankshaft speeds of 1400 and 2300 $\mathrm{rpm}$, respectively. The engine test bench is shown in Fig. 1.

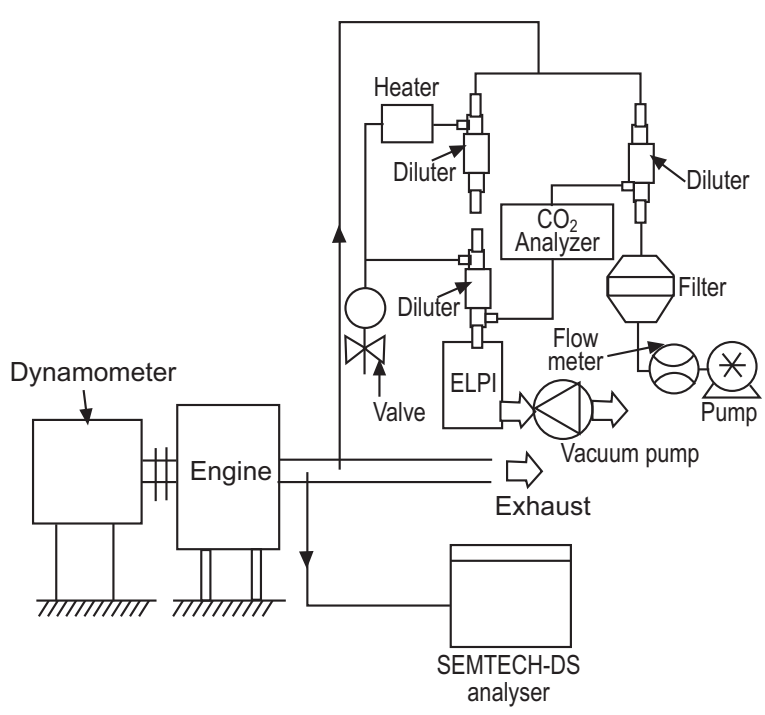

Fig.1. Schematic diagram of test bench.

During the first 4 modes of the cycle, i.e., Mode 1-4, engine was operated at 100, 75, 50 and $10 \%$ of full load at $2300 \mathrm{rpm}$. During the next three modes i.e. Modes $5-7$, engine was run at 100,75 and $50 \%$ of full load at $1400 \mathrm{rpm}$, while the $8^{\text {th }}$ Mode was an idle mode. The baseline measurements were taken by fuelling the engine with locally available (higher sulphur) petroleum diesel. The engine was then fuelled with soybean oilbased biodiesel blended fuels B20 and B50 to get the subsequent measurements. Biodiesel was purchased from the market and its properties were provided by the vender. The sulphur content of $160 \mathrm{ppm}$ and oxygen enrichment are deemed to be the inherited properties of biodiesel depending on its source and origin. The detail of fuel properties are given in Table 1, while the composition of lubricant is as follows: $0.6 \mathrm{ppm} \mathrm{Fe} ; 1.6$ ppm Al; 3.3 ppm Na; 15.3 ppm Mg; 63.9 ppm Mo; 353 ppm Zn; and $>1000$ ppm Ca.

Sampling methodology. The sampling was carried out first for the measurement of nitric oxide $(\mathrm{NO})$ and $\mathrm{NO}_{2}$ 
Table 1. Fuel properties and test method

\begin{tabular}{|c|c|c|c|c|}
\hline Property & Diesel & Biodiesel & Method $^{\mathrm{a}}$ & $\approx \mathrm{ASTM}$ \\
\hline $\begin{array}{l}\text { Viscosity } \\
\left(\mathrm{mm}^{2} / \mathrm{s}\right) \text { at } 20^{\circ} \mathrm{C}\end{array}$ & 4 & 7.1 & GB/T265 & D445 \\
\hline Cetane number & 52 & 60.1 & GB/T386 & D6890 \\
\hline $\begin{array}{l}\text { Sulphur content } \\
\text { (ppm) }\end{array}$ & 350 & 160 & GB/T380 & D4294 \\
\hline $\begin{array}{l}\text { Density }\left(\mathrm{kg} / \mathrm{m}^{3}\right) \\
\text { at } 20^{\circ} \mathrm{C}\end{array}$ & 841 & 875 & GB/T1884-85 & D1298/4052 \\
\hline $\begin{array}{l}\text { Calorific value } \\
(\mathrm{MJ} / \mathrm{kg})\end{array}$ & 42.8 & 37.3 & - & - \\
\hline $\begin{array}{l}\text { Oxygen content } \\
\text { (wt \%) }\end{array}$ & 0.0 & 11.0 & - & - \\
\hline $\mathrm{C}: \mathrm{H}$ & $87: 13$ & $77: 12$ & SH/T 0656-1998 & - \\
\hline
\end{tabular}

$\mathrm{a}=$ standard method used in China.

separately through SEMTECH-DS (USA), then for the analysis of particles, sulphates and TME as per schematic diagram shown in Fig.1. In order to collect the exhaust for the estimation of sub-50 nm and over-50 nm aerosoles, 2 tandem ejector diluters each with a dilution ratio of almost 8:1 were arranged in series, first at $200{ }^{\circ} \mathrm{C}$ and then at ambient temperature. The exhaust was then passed through an ELPI (Dekati, Finland) having a corona charger, an electrometer, and a cascade (Shah et al., 2014). A sampling pump was used to provide flow, while the flow rate was controlled by a controller at about $10 \mathrm{~L} / \mathrm{min}$. The samples for analysis of sulphates and TME were trapped in Teflon membrane filter (Teflo, Pall Corporation), having diameter and pore size of $47 \mathrm{~mm}$ and $0.2 \mu \mathrm{m}$, respectively. Prior to the filter, exhaust was led to pass through an ejector diluter similar to that discussed earlier at a temperature of about $100{ }^{\circ} \mathrm{C}$. A battery operated pump was engaged there to keep the volume flow rate of the sample at $80 \mathrm{~L} / \mathrm{min}$. The filters containing the trapped pollutants were stored for further processing. Total 3 samples $(n=3)$ were collected for each analysis of sulphates and TME, while 3 measurements were also taken for each category of sub-50 nm and over-50 nm aerosols and the $\mathrm{NO}_{2} / \mathrm{NO}_{\times}$ratios. Thus pollutants in the current study are calculated and subsequently discussed on the basis of their mean values.

Analysis of pollutants. One half part of the sampled material was put into Teflon vessel after cutting it into several pieces which were then soaked up into $2 \mathrm{~mL}$ nitric acid $\left(\mathrm{HNO}_{3}\right)$ for 5 mins. This sample was finally dissolved into $1 \mathrm{~mL}$ distilled hydrochloric acid $(\mathrm{HCl})$ to get a solution of $10 \mathrm{~mL}$ in a standard flask. The trace metal emission (TME) such as sodium $(\mathrm{Na})$, potassium $(\mathrm{K})$, aluminum $(\mathrm{Al})$, calcium $(\mathrm{Ca})$, magnesium $(\mathrm{Mg})$, chromium $(\mathrm{Cr})$, titanium (Ti), manganese $(\mathrm{Mn})$, iron (Fe), sulphur (S), strontium (Sr), nickel (Ni), zinc (Zn), lead $(\mathrm{Pb})$ and copper $(\mathrm{Cu})$ were analysed using the inductively coupled plasma (ICP)-atomic emission, spectroscopy, (VARIN VISTA-MPX).

The second half part of the filter was taken into a centrifuge tube after cutting it into numerous pieces. The sampled material was immersed into $15 \mathrm{~mL}$ distilled and deionised water, and then sonicated (agitated for particles) for 20 mins. For the purification of the extract, a microcellular membrane filter (Pall Corporation) was used. The same procedure was repeated to get another extract of the sampled material. Finally, both extracts were mixed together for the subsequent analysis of pollutants. The sulphates were then quantified by using the ion chromatography (Dionex USA).

\section{Results and Discussion}

The size of the particles measured by an ELPI ranges from 0.03 to $10 \mu \mathrm{m}$ aerodynamic diameters available from 12 channels. The particle sizes in these 12 categories are as follows: $0.021,0.039,0.072,0.121,0.203,0.317$, $0.486,0.766,1.234,1.96,3.10$, and $6.32 \mu \mathrm{m}$. In the current study, aerosols of first 2 sizes i.e. $0.021 \mu \mathrm{m}$ and $0.039 \mu \mathrm{m}$ are discussed as sub-50 $\mathrm{nm}$ aerosols (nuclei mode), while the subsequent 6 sizes ranging from 0.072 $\mu \mathrm{m}$ to $0.766 \mu \mathrm{m}$ are summed up under over-50 nm aerosols (accumulation mode) category. However, their number-size distributions have been addressed elsewhere (Shah et al., 2009c)

Emissions of aerosols. Over-50 nm aerosols were generally reduced with both B20 and B50 fuels as compared to petroleum diesel during the whole cycle of operation as shown in Fig. 2. The rate of reduction is $8.7-47 \%$ with $\mathrm{B} 20$ and $6-51 \%$ with $\mathrm{B} 50$, relative to baseline measurements. B50 blend gave more control on this category of pollutants as compared to B20. The reduction rate is remarkably high during the medium load modes such as Mode 3 and Mode 7 with both the blends of biodiesel. Moreover, these pollutants are predominant at higher loads as compared to lower ones with all the three fuels. In addition to this, particles are dominant at maximum speed (2300 rpm) modes, relative to lower speed (1400 rpm) modes.

The higher reduction rates with biodiesel blended fuels in general, and with B50 in particular are most likely due to the elevated $\mathrm{NO}_{2} / \mathrm{NO}_{\times}$ratios with the blended fuels relative to neat diesel, as shown in Fig. 2. The 


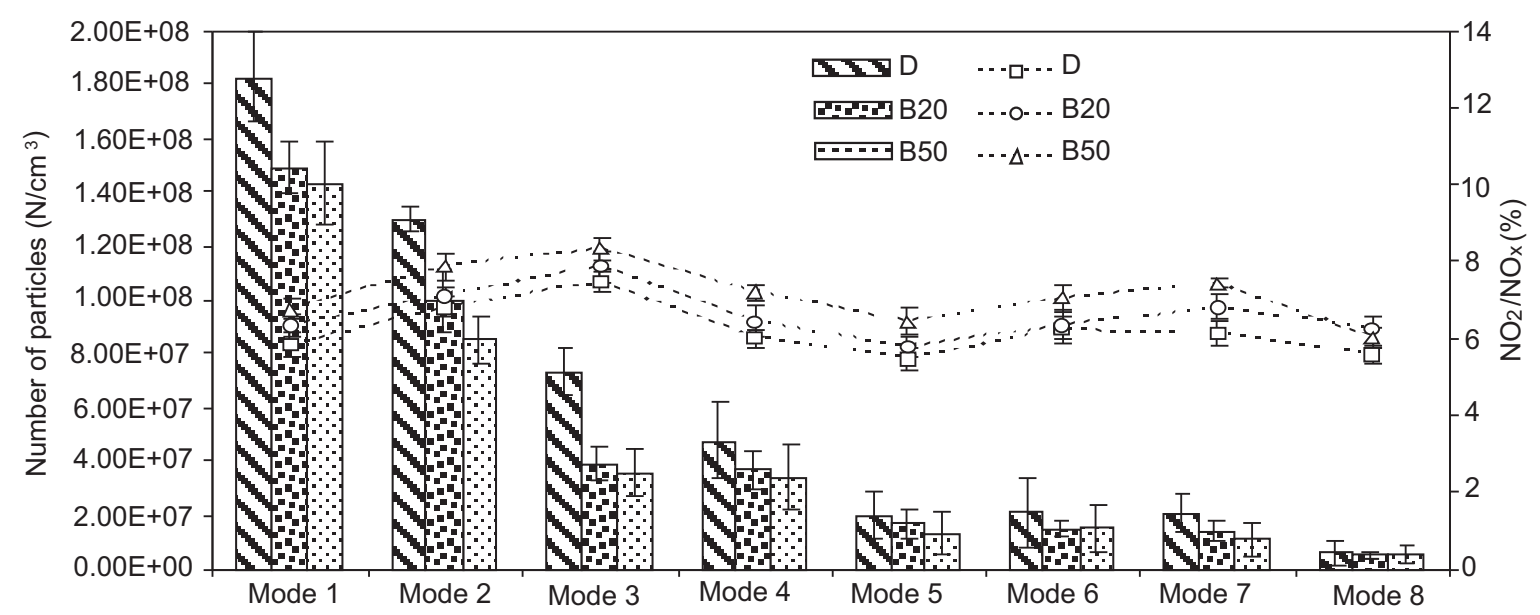

Fig. 2. Over-50 nm aerosols and $\mathrm{NO}_{2} / \mathrm{NO}_{\times}$ratio comparisons at different test modes.

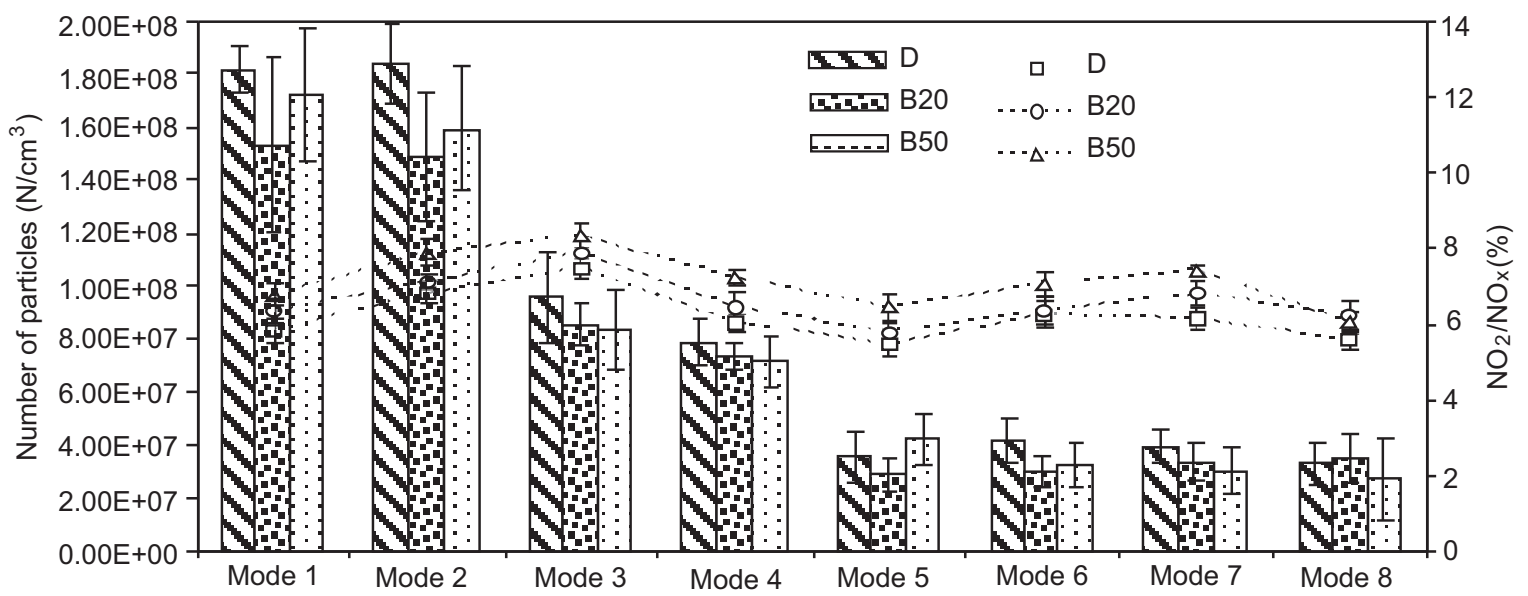

Fig. 3. Sub-50 nm aerosols and $\mathrm{NO}_{2} / \mathrm{NO}_{\times}$ratio comparisons at different test modes.

ratios are higher in the case of $\mathrm{B} 50$ relative to $\mathrm{B} 20$ during all the cyclic modes except the idle mode. Biodiesel inherits oxygen content which promotes the oxidation of $\mathrm{NO}$ to $\mathrm{NO}_{2}$, with the consequent higher $\mathrm{NO}_{2} / \mathrm{NO}_{\times}$ratios. The elevated $\mathrm{NO}_{2} / \mathrm{NO}_{\times}$ratio may further increase the combustion of soot and soluble parts of $\mathrm{PM}$, as soot combustion is accelerated with $\mathrm{NO}_{2}$ relative to oxygen itself (Setiabudi et al., 2004). Thus presence of both oxygen (fuel-bound oxygen) and $\mathrm{NO}_{2}$ are responsible for the controlling of over-50 nm aerosols in case of both B20 and B50 as compared to D. In addition to this, higher cetane number of biodiesel decreases the ignition lag/delay with the consequent earlier combustion of fuel with biodiesel and its blends relative to their counterpart diesel fuel. This further leads to higher MCP in the cylinder, and thus more complete combustion resulting in reduced $\mathrm{PM}$ emissions, particularly in over- $50 \mathrm{~nm}$ aerosols. It has already been demonstrated that, PM is decreased up to $80 \%$ and $21 \%$ with neat biodiesel and B20, respectively (Shah et al., 2009a). Moreover, the higher viscosity of biodiesel $\left(7.1 \mathrm{~mm}^{2} / \mathrm{s}\right)$ causes the reduction of fuel losses in the injector resulting in quicker development of pressure with improved injection timing (Tsolakis, 2006). Shah et al. (2010) have reported that higher fuel injection pressure with B20 causes a rapid increase of injection flow rate together with higher injection velocity, kinetic energy and momentum of droplet resulting in larger penetration distance in the combustion chamber. Consequently, better atomisation, and hence better airfuel mixing takes place with biodiesel and its blends.

The elevated emissions at higher loads are most probably due to the incomplete combustion of the carbonaceous part of PM caused by the minimised relative air/ fuel ratio $\lambda$ (lambda) or rich mixture formation (Liu et al., 2011). The higher pollutants at maximum speed modes, on the other hand, are attributed to higher soot formation because of the weak oxidation rate caused 
by the decrease in temperature. It is well documented that turbulences inside the combustion chambers are increased at higher engine speeds which further cause the increase in heat losses (Collier et al., 1995).

Moreover, the ELPI data reflects the relatively higher uncertainty levels. The possible reasons of this uncertainty may be one or more than one of the following factors: (i) the condensation of high concentrated and temperature exhaust, (ii) reduction in pressure of high effective particle air (HEPA), (iii) preheating of primary dilutor to a temperature less than $195^{\circ} \mathrm{C}$, (iv) variation in dilution ratio, (v) any problem in charging and collection mechanisms i.e., mishandling during particle charging, (vi) wrong inertial classification in a cascade impactor and (vii) the electrical detection of aerosol particles, etc.

Emissions of sub-50 $\mathbf{~ n m}$ aerosols. It is important to discuss the sub-50 $\mathrm{nm}$ aerosols of PM on account of their potential hazards to the environment and human beings. As the diameters of particles are decreased into nano-sizes, their probability to be inhaled is increased. Sub-50 nm aerosols are predominant at maximum load modes of both cyclic speeds (i.e. Mode 1 and Mode 5) with B50 relative to other two fuels as shown in Fig. 3. However, B20 gives a better control of the pollutants during these modes. Generally, both blends show diminished emissions of sub$50 \mathrm{~nm}$ aerosols, and relative reduction rate is $14-32 \%$ with $\mathrm{B} 20$ and $4-15.8 \%$ with $\mathrm{B} 50$. Contrary to the particle trends, $\mathrm{NO}_{2} / \mathrm{NO}_{\times}$ratios reveal the order of magnitude as B50, B20, and then diesel. This leads to an interesting finding that unlike B20, B50 does not show much relevance to the $\mathrm{NO}_{2} / \mathrm{NO}_{\times}$ratios. It has also been reported in previous study (Shah et al., 2014) that sub-50 nm aerosols (nuclei mode particles) are not directly affected by $\mathrm{NO}_{2} / \mathrm{NO}_{x}$ ratios, and thus remain higher with neat biodiesel, relative to diesel.

Neat biodiesel may promote the heterogeneous nucleation owing to oxygen enrichment (Shah et al., 2009c). This phenomenon is more significant during higher load modes due to the burning of rich mixture. Although biodiesel has lower sulphur contents as compared to diesel, this available quantity along with that carried by lube oil was oxidised to sulphur dioxide $\left(\mathrm{SO}_{2}\right)$ in the presence of oxygen contents. Subsequently, $\mathrm{SO}_{2}$ was converted to sulphur trioxide $\left(\mathrm{SO}_{3}\right)$, and then to sulphuric acid $\left(\mathrm{H}_{2} \mathrm{SO}_{4}\right)$ nuclei in the presence of diluting air and water. Thus, the adsorption phenomenon of such inorganic nuclei was promoted leading to the proliferation of heterogeneous nucleation with higher level blends (Shah et al., 2014). Kittelson (1998) has reported that nuclei mode particles are formed during the nucleation process caused by dilution and cooling of the engine exhaust. It has been experimentally proved earlier that the concentrations of nucleation mode particles are predominant with neat biodiesel and B20 relative to petroleum diesel (Shah et al., 2009c)

Sulphates. It is pertinent to note that the maximum load modes at which emissions of sub-50 nm aerosols were higher with $\mathrm{B} 50$ as discussed earlier, the sulphates too remain elevated at the same as shown in Fig. 4. The relative increase is $9 \%$ and $13 \%$ at Mode 1 and Mode 5, respectively. However, these pollutants remain lower during all other cyclic modes with both blended fuels relative to their counterpart. The relative decrease varies by $3-12 \%$ with $\mathrm{B} 20$ and $4.5-16 \%$ with $\mathrm{B} 50$.

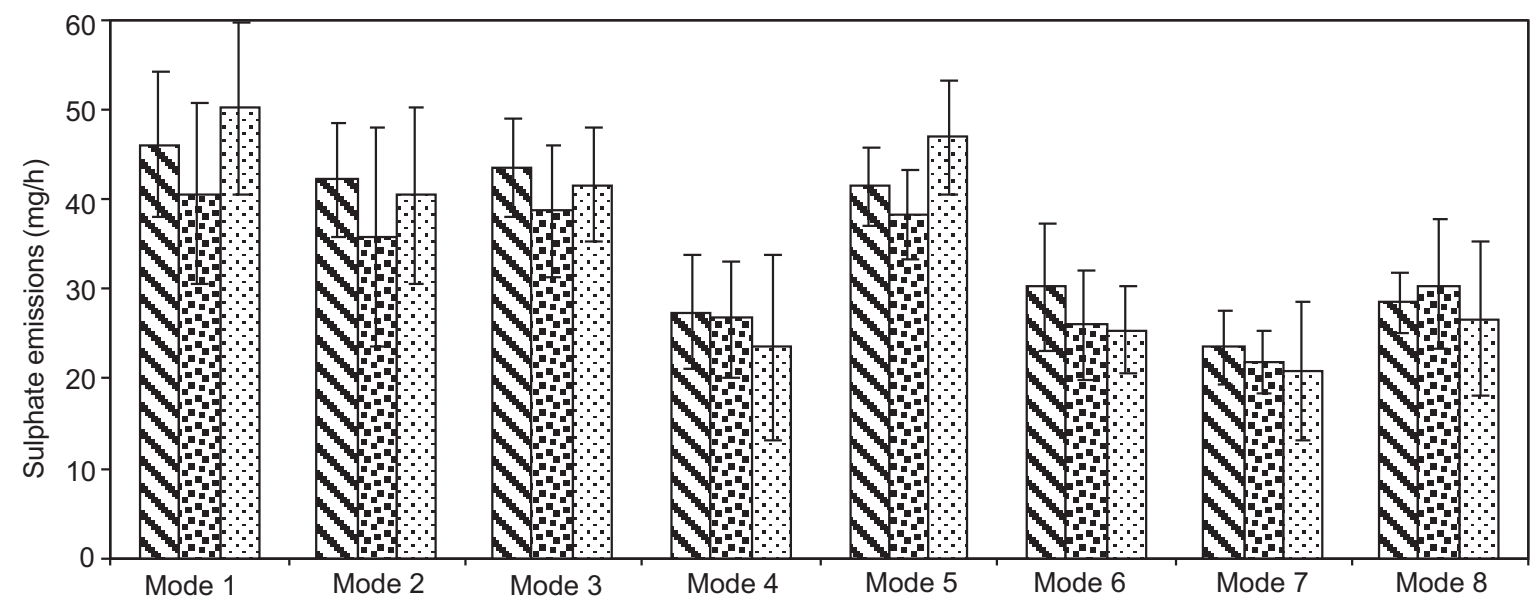

$\triangle \mathrm{D}$ B20 B50

Fig. 4. Comparison of sulphate emissions at different test modes. 
These findings i.e predominance of sulphate emissions at maximum load modes further ratifies the argument that, it is actually heterogeneous nucleation which increases both nuclei mode NP as well as sulphate emissions. Oxygen enrichment in biodiesel promotes the oxidation of sulphur (available in lube oil and in fuel as traces) to $\mathrm{SO}_{2}$ in a very similar fashion as $\mathrm{NO}$ is oxidised to $\mathrm{NO}_{2}$, and thus leads to the heterogeneous or inorganic nucleation. Consequently, the sulphate nano-particles are increased at maximum load modes in case of higher biodiesel blend B50 as compared to lower blend B20.

Meanwhile, the decrease in sulphate pollutants with both blends of biodiesel during all other test modes may be due to the more complete combustion owing to better physicochemical properties of biodiesel relative to conventional diesel. Thus the modes other than that at $100 \%$ load develop the temperatures in the combustion chamber which are prone to the decomposition of PM, especially to soot and sulphates.

Trace metals. Trace metal is an important class of pollu-tants which along with some other substances contribute $8 \%$ to total PM emissions (Agarwal, 2007). Although this percentage contribution to PM is low, the toxicity or perniciousness to human health associated with TME is significant (Becker et al., 2005). Crust elements such as $\mathrm{Al}, \mathrm{Ca}, \mathrm{Mg}, \mathrm{Si}$ and $\mathrm{Fe}$ contribute about $82 \%$ to total metals of petroleum diesel (Wang et al., 2003). Figure 5 presents the TME and their reduction rates with $\mathrm{B} 20$ and $\mathrm{B} 50$ relative to baseline measurements during the various cyclic modes. Both of the biodiesel blends give significant control over these pollutants, and the reduction rates vary by $42-57 \%$ with B20 and $64-80 \%$ with B50. It is quite obvious that higher blended fuel i.e. B50 gives substantial control over TME as compared to B20. Thus, higher the percentage of biodiesel in a blend, the greater will be the reduction in TME. This finding is consistent with the previous study (Shah et al., 2014) that neat biodiesel presents $65 \%$ to above $85 \%$ reduction in TME. These reduction rates, of course, endorse that biodiesel is more benign to both environment and human health.

The study of the effect of biodiesel on TME has further been extended to individual species to gain a deep insight into the biodiesel role in the alteration of trace metal composition. Two important modes, i.e., Mode 3 (50\% of full load at $2300 \mathrm{rpm}$ ) and Mode 7 (50\% of full load at $1400 \mathrm{rpm}$ ), were selected for this purpose. It is clear that $\mathrm{Ca}$ and $\mathrm{Fe}$ are predominant components with diesel and $\mathrm{B} 20$, while $\mathrm{Na}$ is the dominant element in case of both blended fuels. B20 and B50 give a good control over $\mathrm{Ca}$ and $\mathrm{Fe}$, but $\mathrm{Na}$ is increased with both the blends (Fig 6). The relative decrease in $\mathrm{Ca}$ is $53-70 \%$ and 68 $79 \%$ with B20 and B50, respectively. Similarly, the relative decrease in $\mathrm{Fe}$ is up to $55 \%$ with B20 and $90 \%$ with B50 during the selected modes of the test cycle. The relative rise in $\mathrm{Na}$, on the other hand, is up to $64.5 \%$ and $76 \%$ with B20 and B50, respectively.

The abatement in $\mathrm{Ca}$ with biodiesel blends may be due to the better physicochemical properties of biodiesel such as reduced ignition delay, improved cetane number, earlier start of injection, higher MCP, higher rate of pressure rise, better air-fuel mixing and heat release, and oxygen enrichment causing the better oxidation rate of $\mathrm{Ca}$. It is

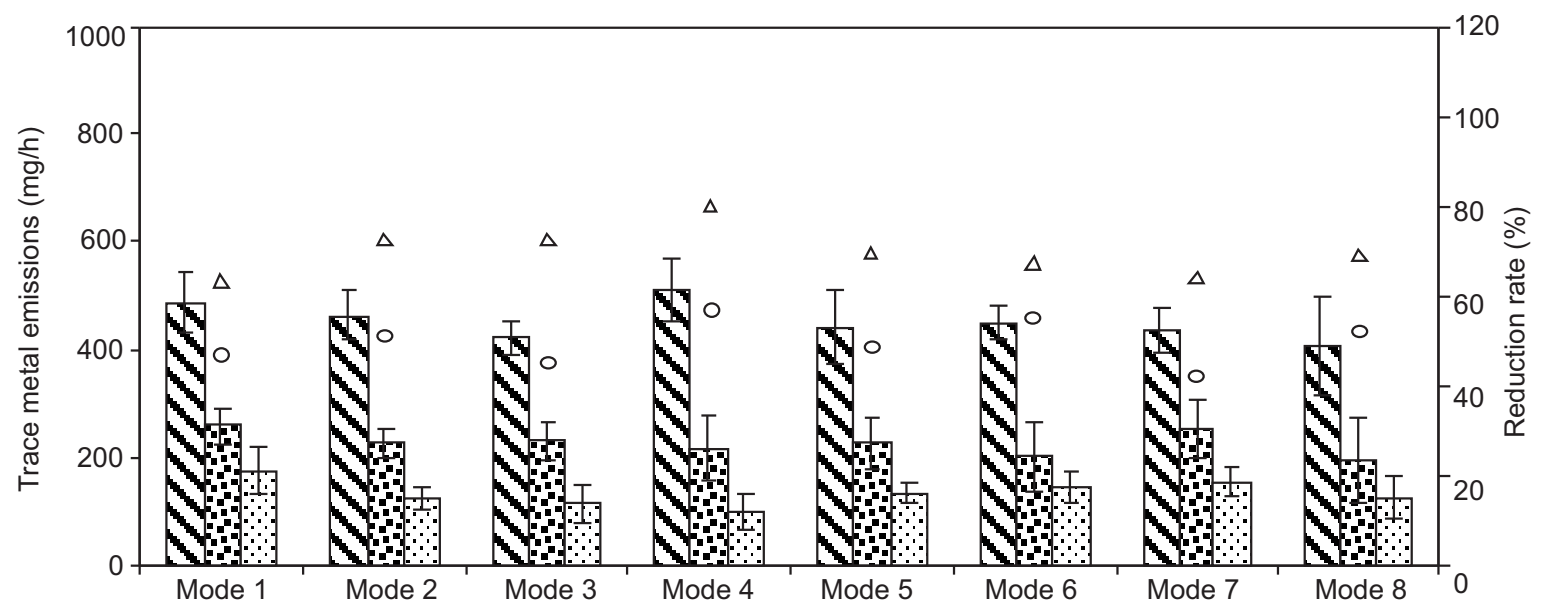

$\triangle \mathrm{D} E \mathrm{~B} 20 \quad \therefore \mathrm{B} 50$ О В20 $\Delta \mathrm{B} 50$

Fig. 5. Comparison of TME and reduction rate at various modes. 


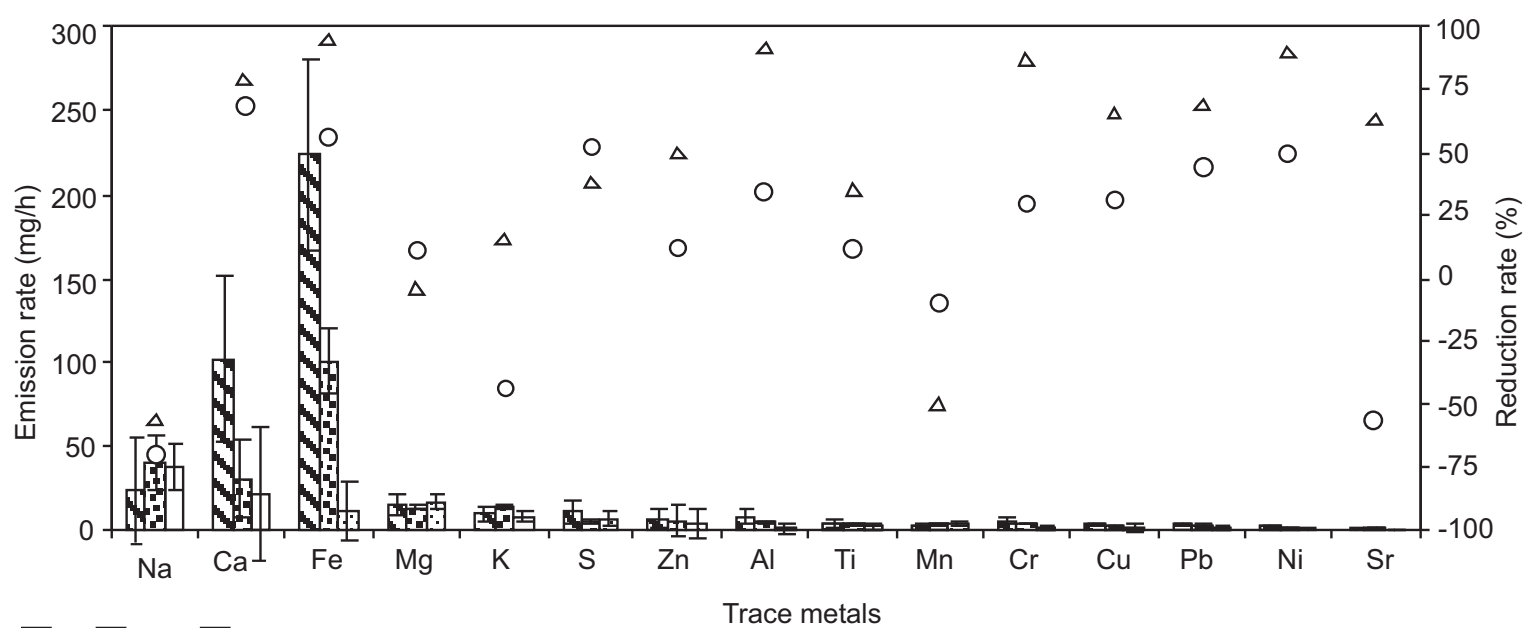

$\mathrm{AD}$ В $\mathrm{B} 20 \mathrm{~B} 50$ O В20 $\triangle \mathrm{B} 50$

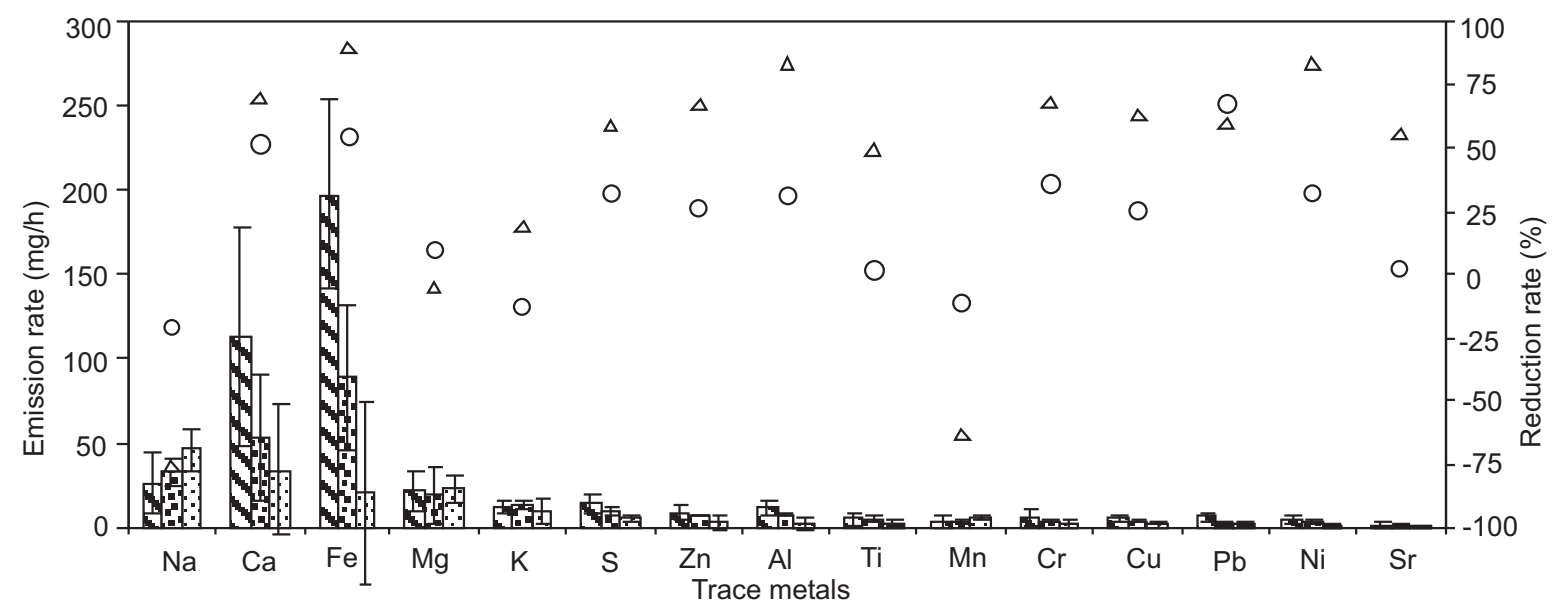

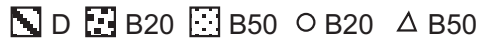

Fig. 6. Comparison of individual trace metals and their reduction rates at Mode 3 and 7.

conjectured that the higher content of Ca (i.e., > $1000 \mathrm{ppm}$ ) in lubricating oil along with other additives in petroleum diesel may have adversely affected the quality of fuel from $\mathrm{Ca}$ viewpoint, and thus lead to higher $\mathrm{Ca}$ emissions in this case. The signi-ficant decrease in $\mathrm{Fe}$ emission rates with these blends is probably due to the relative decrease in wear rates of the engine in case of B20 and B50. Agarwal (2007) is of the view that the wear rates of different parts of engine such as piston-rings, piston, cylinder-liner, etc. are remarkably decreased with biodiesel on account of additional lubricity possessed by it. The elevated rates of $\mathrm{Na}$ emissions with biodiesel blends, on the other hand, are ascribed to sodium hydroxide $(\mathrm{NaOH})$ used as a catalyst during the transesterification process of biodiesel.

\section{Conclusion}

The effect of biodiesel on the PM composition constituted by nuclei and accumulation mode particles, sulphates, and TME was investigated. A turbocharged inter-cooled direct injection type compression ignition engine was connected to an AC electrical dynamometer to operate under the auspices of the Chinese steady state cycle on a test bench. The engine was first operated on commer-cial diesel, then on B20 and B50, respectively, to collect the required samples of pollutant for their subsequent analysis. According to the experimental results, over- $50 \mathrm{~nm}$ aerosols were decreased by 8.7 $47 \%$ and $6-51 \%$ with B20 and B50, respectively, as compared to baseline measurements on account of elevated $\mathrm{NO}_{2} / \mathrm{NO}_{\times}$ratios. The abatement of this category of pollutants remained remarkably at medium load modes. The sub-50 $\mathrm{nm}$ aerosols and sulphates were decreased by $14-32 \%$ and $3-12 \%$, respectively, with B20, but increased with B50 during maximum load modes owing to higher percentage (by volume) of biodiesel which promoted the heterogeneous 
nucleation. In addition to this, TME were highly reduced with $\mathrm{B} 20$ and $\mathrm{B} 50$ and the respective reduction rates varied by $42-57 \%$ and $64-80 \%$. The most abundant TME such as $\mathrm{Ca}$ and Fe were highly reduced, while $\mathrm{Na}$ increased in case of blended fuels relative to diesel.

\section{Acknowledgement}

Authors are thankful to Dr. He Chao and Dr. Liu ZhiHua for their helping and encouraging attitude during the operation of ion chromatography and ICP-atomic emission spectroscopy. Our thanks are also due to the National Natural Science Foundation (NNSF) of China under grant \# 50576063.

\section{References}

Agarwal, A.K. 2007. Biofuels (alcohols and biodiesel) applications as fuels for internal combustion engines. Progress in Energy and Combustion Science, 33: 233-271.

Agarwal, A.K., Das, L.M. 2001. Biodiesel development and characterization for use as a fuel in compression ignition engine. Journal of Engineering for Gas Turbines and Power, 123: 440-447.

Becker, S., Dailey, L.A., Soukup, J.M., Grambow, S.C., Devlin, R.B., Huang, Y.C. 2005. Seasonal variations in air pollution particle-induced inflamatory mediator release and oxidative stress. Environment Health Perspective, 113: 1032-1038.

Burtscher, H. 2005. Physical characterization of particulate emissions from diesel engines: a review. Journal of Aeosole Science, 36: 896-932.

Collier, A.R., Rhead, M.M., Trierand, C.J., Bell, M.A. 1995. Polycyclic aromatic compound profiles from a light-duty direct-injection diesel engine. Fuel, 74: 362-367.

Donaldson, K., Li, X.Y., MacNee, W. 1998. Ultrafined (manometer) particle mediated lung injury. Journal of Aerosol Science, 29: 553-560.

Dorado, M.P., Ballesteros, E., Arnal, J.M., Gomez, J., Gimenez, F.J.L. 2003. Testing waste olive oil methyl ester as a fuel in a diesel engine. Energy and Fuels, 17: 1560-1565.

He, C., Ge, Y.S., Tan, J.W., You, K.W., Han, X.K., Wang, J.F., You, Q., Shah, A.N. 2009. Comparison of carbonyl compounds emissions from diesel engine fuelled with biodiesel and diesel. Atmospheric Environment, 24: 3657-3661.

Jha, S.K., Fernando, S., Filip, T.S.D. 2008. Flame temperature analysis of biodiesel blends and components. Fuel, 87: 1982-1988.

Karabektas, M.P., Ergen, G., Hosoz, M. 2008. The effects of preheated cottonseed oil methylester on the performance and exhaust emissions of a diesel engine. Applied Thermal Engineering, 28: 21362143.

Kittleson, D.B. 1998. Engine and nanoparticles: a review. Journal of Aerosol Science, 29: 575-588.

Lee, C.S., Park, S.W., Kwon, S. 2005. An experimental study on the atomozation and combustion characteristics of biodiesel-blended fuels. Energy \& Fuels, 19: 2201-2208.

Lim, M., Ayoko, G., Morawska, L., Ristovski Z., Jayaratne, E., Kokot, S. 2007. The effects of fuel characteristics and engine operating conditions on the elemental composition of emissions from heavy duty diesel buses. Fuel, 86: 1831-1839.

Lin, Y.C., Lee, W.J., Wu, T.S., Wang, C.T. 2006. Comparison of PAH and regulated harmful matter emissions from biodiesel blends and paraffinic fuel blends on engine accumulated mileage test. Fuel, 85: 2516-2523.

Liu, Z.H., Shah, A.N., Ge, Y.S., Ding, Y., Tan, J.W., Jiang, L., Yu, L., Zhao, W., Wang, C., Zeng, T. 2011. Effects of continuously regenerating diesel particulate filters on regulated emissions and number-size distribution of particles emitted from a diesel engine. Journal of Environmental Sciences, 23: 798-807.

Rahman, H., Ghadge, S.V. 2007. Performance of compression ignition engine with mahua (Madhuca indica) biodiesel. Fuel, 86: 2568-2573.

Setiabudi, A., Makkee, M., Moulijn, J.A. 2004. The role of $\mathrm{NO}_{2}$ and $\mathrm{O}_{2}$ in the accelerated combustion of soot in diesel exhaust gases. Applied Catalysis B: Environmental, 50: 185-194.

Shah, A.N., Ge, Y., Shah, F.H., Mughal, H.U., Rahman, Z.U., Naveed, A. 2014. Effect of biodiesel on particulate numbers and composition emitted from turbocharged diesel engine. International Journal of Environmental Science and Technology, 11: 385-394.

Shah, A.N., Ge, Y., Jiang, L. 2011. Impact of a ureaselective catalytic reduction system on volatile organic compound emissions from a diesel engine. The Arabian Journal for Science and Engineering, 36: 891-901.

Shah, A.N., Ge, Y., He, C. 2010. Macroscopic spray characteristics of diesel and biodiesel-diesel blend: An experimental comparison. Journal of Engineering \& Applied Sciences, 29: 35-47. 
Shah, A.N., Ge, Y., Tan, J.W., He, C. 2009a. Effects of biodiesel from soyabean oil on the exhaust emissions of a turbocharged diesel engine. Pakistan Journal of Scientific and Industrial Research, 52: 217-227.

Shah, A.N., Ge, Y., Tan, J.W., Liu, Z.H. 2009 b. Experimental investigation of VOCs emitted from DI-CI engine fuelled with biodiesel, diesel and biodiesel-diesel blend. Pakistan Journal of Scientific and Industrial Research, 52: 158-166.

Shah, A.N., Ge, Y., Jiang, Shaikh, M.A. 2009c. An experimental study on number size distribution of particles emitted from a heavy duty CI engine fuelled with biodiesel and its $20 \%$ blend. Mehran University Research Journal of Engineering \& Technology, 28: 205-214.

Shah, A.N., Ge, Y., Tan, J.W., Liu, Z.H. 2008. An experimental investigation of $\mathrm{PAH}$ emissions from a heavy duty diesel engine fuelled with biodiesel and its blends. Pakistan Journal of Scientific and Industrial Research, 51: 293-300.

Szybist, J.P., Song, J., Alam, M., Boehman, A.L. 2007.

Biodiesel combustion, emissions and emission control. Fuel Process Technology, 88: 679-691.

Tsolakis, A. 2006. Effects on particle size distribution from the diesel engine operating on RME-biodiesel with EGR. Energy \& Fuels, 20: 1418-1424.

Turrio-Baldassarri, L., Battistelli, C.L., Conti, L., Crebelli, R., De Berardis, B., Iamiceli, A.L., Gambino, M., Iannaccone, S. 2004. Emission comparison of urban bus engine fueled with diesel oil and biodiesel blend. The Science of the Total Environment, 327: 147-162.

Usta, N. 2005. An experimental study on performance and exhaust emissions of a diesel engine fuelled with tobacco seed oil methyl ester. Energy Conversion and Management, 46: 2373- 2386.

Wang, Y.F., Huang, K.L., Li, C.T., Mi, H.H., Luo, J.H., Tsai, P.J. 2003. Emissions of fuel metals content from a diesel vehicle engine. Atmospheric Environment, 37: 4637-4643.

Wong, C.P., Chan, T.L., Leung, C.W. 2003. Characterization of diesel exhaust particle number and size distributions using mini-dilution tunnel and ejector-diluter measurement techniques. Atmospheric Environment, 37: 4435-4446.

Zhao, H., Ge, Y., Wang, X., Tan, J., Wang, A., You, K. 2010. Effects of fuel sulfur content and diesel oxidation catalyst on PM emitted from light-duty diesel engine. Energy \& Fuels, 24: 985-991. 